\title{
MANAJEMEN PENGEMBANGAN DOSEN SEBAGAI UPAYA MENINGKATKAN MUTU SEKOLAH TINGGI PARIWISATA AMPTA YOGYAKARTA
}

\author{
Siti Rokhmi Lestari \\ Dosen Sekolah Tinggi Pariwisata AMPTA Yogyakarta
}

\begin{abstract}
The aim of this study is to describe the planning and development of lecturers human resources in AMPTA Tourism School as well as to know the profesionalism of lecturers and quality assurance in the AMPTA Tourism School of Yogyakarta. From this study it can be concluded that, in general, human resource planning and development of lecturers as well as quality assurance in AMPTA Tourism School have not been fully implemented in accordance with the existing regulations and legislation.

However, AMPTA Tourism School is on the right track in terms of lecturers profesionalism development and networking establisment with external stakeholders. Implementation of human resources development is carried out through formal and informal ways.
\end{abstract}

Keywords: Management, Human Resources Development, Lecturer, Quality, Tourism School.

\section{PENDAHULUAN}

Pendidikan (baca: perguruan tinggi) yang berkualitas adalah institusi yang melahirkan output-nya sesuai dengan kebutuhan (need) dan keinginan (want) stakeholders. Lembaga-lembaga tersebut mengemas pendidikannya dengan kualitas/ mutu, kompetensi, keunggulan, kompetitif, dan profesional. Output yang berkualitas ditentukan oleh mutu input dan proses (Mulyono, 2008).

Terwujudnya pendidikan yang bermutu dibutuhkan SDM yang berkualitas, berkompeten di bidangnya, berakhlak mulia, dan profesional. Lahirnya SDM yang kompetitif dan berkualitas tidak terlepas dari peran dosen yang profesional sebagai aktor penentu bermutunya sebuah perguruan tinggi.

Foulkes dalam Dessler (2003) memprediksi bahwa peran SDM dari waktu ke waktu akan semakin strategis. "For many years it has said that capital is the bottleneck for a developing industry. I don't think this any longer holds true. I think it's the work force and the company's inability to recruit and maintain a good work force that does constitute the bottleneck for production. I think this will bold true even more in the future."

Oleh karena itu, SDM merupakan salah satu unsur yang paling vital bagi organisasi. Tidak terkecuali bagi industri pariwisata sebagai sektor yang memiliki hubungan langsung secara intangible dengan konsumen sangat bergantung pada kemampuan dan keterampilan SDM pariwisata. Apalagi, John Naisbitt dalam bukunya Global Paradox mengatakan bahwa pariwisata dapat dikategorikan sebagai industri terbesar dunia (The World's Largest Industry .

Sebagai produk jasa/service based organization, keberadaan SDM (people) pariwisata sangat penting, yaitu pertama, sebagai motor penggerak kelangsungan industri pariwisata, kedua, sebagai pelaku utama yang menciptakan produk inti 
pariwisata (pengalaman), dan ketiga, sebagai salah satu faktor penentu daya saing industri pariwisata (Evans, Campbell, \& Stonehouse, 2003; Lynch, 2000 dalam Menpora, 2009).

Saat ini keberadaan SDM pariwisata Indonesiamendudukiperingkatketiga setelah Singapura dan Malaysia. Maka pemerintah terus berupaya meningkatkan kualitas SDM pariwisata Indonesia dalam hal penyediaan, pembinaan, dan pengembanagn SDM pariwisata, salah satunya melalui lembaga pendidikan pariwisata yang bermutu.

Untuk memenuhi kebutuhan perkembangan industri pariwisata tersebut, lembagapendidikan tinggipariwisata dituntut untuk melakukan peningkatan kualitas pengajar, peningkatan sarana prasarana, dan perbaikan sistem serta kurikulum pengajaran yang bisa mengakomodasi kebutuhan keilmuan, keterampilan, dan kompetensi pangsa pasar. Salah satu permasalahan yang dihadapi adalah rendahnya ketersediaan tenaga pendidikan (instruktur) yang memenuhi kualifikasi yang diterapkan oleh pemerintah, khususnya untuk tingkat pendidikan tinggi pariwisata.

Sebagaimana diketahui bahwa saai ini pemerintah menetapkan kualifikasi S-2 sebagai persyaratan minimal untuk menjadi tenaga pengajar (dosen) pada lembaga pendidikan tinggi pariwisata. Padahal, selama ini sumber tenaga pengajar di banyak lembaga pendidikan tinggi pariwisata berasal dari industri pariwisata yang pada umumnya tidak memiliki kualifikasi pendidikan sebagaimana yang dipersyaratkan. Di samping itu, karena belum banyak perguruan tinggi yang membuka program S-2 pariwisata menyebabkan para pengajar melanjutkan studi pada jurusan yang kurang relevan dengan kebutuhan lembaga pendidikan tinggi.

Dalam proses penjaminan mutu di perguruan tinggi dibutuhkan peran dosen yang berkualitas. SDM dosen merupakan faktor sentral dalam organisasi lembaga perguruan tinggi. Dosen merupakan salah satu komponen pembentuk karakter bangsa bagi lulusan yang paling vital dalam menentukan mutu perguruan tinggi. Dosen dalam setiap aktivitasnya akan berhubungan dengan pendidikan-pembelajaran, penelitian, dan pengabdian kepada masyarakat sebagai implementasi dari tridharma perguruan tinggi.

Saat ini, perencanaan dan pengembangan dosen yang berbasis bidang studi masih belum sesuai dengan yang diharapkan, baik dari segi jumlah, bidang, kualifikasi, dan kualitas/mutu. Maka, setiap perguruan tinggi harus melaksanakan manajemen dosen dengan baik, termasuk Sekolah Tinggi Pariwisata AMPTA Yogyakarta merupakan institusi pendidikan tinggi swasta di Yogyakarta yang tengah merintis jalan untuk menuju perguruan tinggi pariwisata yang bermutu.

Saat ini Sekolah Tinggi Pariwisata AMPTA Yogyakarta yang berbasis pada nilai-nilai dan jiwa enterpreneurship serta menerapkan kurikulum berbasis kompetensi tengah berbenah mulai dari faktor internal yang mencakup keseluruhan kehidupan organisasi yang dikendalikan, baik oleh pimpinan maupun oleh anggota organisasi (dosen, karyawan, dan mahasiswa) yang bersangkutan. Faktor-faktor internal meliputi visi, misi, tujuan, pembakuan sistem manajemen, standar jaminan mutu, hingga pengembangan dosen.

\section{RUMUSAN MASALAH}

Dari latar belakang masalah di atas rumusan masalah yang diangkat dalam penelitian ini adalah bagaimana pengembangan Dosen dalam upaya meningkatkan mutu Sekolah Tinggi Pariwisata AMPTA Yogyakarta?

\section{TUJUAN PENELITIAN}

1. Menjelaskan bagaimana pelaksanaan pengembangan dosen Sekolah Tinggi 
Pariwisata AMPTA Yogyakarta.

2. Menjelaskan bagaimana hasil yang dicapai atas kinerja/profesionalisme dosen dan penjaminan mutu di Sekolah Tinggi Pariwisata AMPTA Yogyakarta.

\section{LANDASAN TEORI}

Banyak pengertian tentang Manajemen SDM (MSDM), antara lain ada yang mengistilahkan human resources, man power management, dan personalia. Dessler (2003) mendefinisikan MSDM "human resource management is the process of acquiring, training, appraising, and compensating employees, and attending to their labor relations, health and safety, and fairness concerrns."

Dari berbagai sumber referensi (Stoner 1995; Sutrisno 2009; Mathis dan Jackson 2002; Jones and Donald L.W. 2008) dapat diuraikan bahwa Manajemen SDM merupakan perencanaan, pengorganisasian, pengarahan, dan pengawasan atas pengadaan, pengembangan, kompensasi, pengintegrasian, pemeliharaan, dan pemutusan hubungan kerja dengan maksud untuk mencapai tujuan organisasi secara terpadu.

Manajemen SDM yang dikaitkan dengan institusi perguruan tinggi merupakan ilmu dan seni yang mengatur pemanfaatan SDM seperti pimpinan, dosen, karyawan, dan mahasiswa secara efektif dan efisien untuk mencapai visi, misi, dan tujuan lembaga pendidikan tinggi secara maksimal. Manajemen SDM dosen dapat meningkatkan kompetensi dan profesionalisme dosen yang pada akhirnya akan memengaruhi peningkatan mutu perguruan tinggi.

Menurut Undang-Undang Nomor 10 Tahun 2009 tentang Kepariwisataan, pengertian SDM dapat terkait dengan Pariwisata, Kepariwisataan, dan Industri Pariwisata. SDM pariwisata adalah seluruh aspek manusia yang mendukung kegiatan wisata, baik yang bersifat tangible maupun intangible yang bertujuan untuk memenuhi kebutuhan dan mewujudkan terciptanya kepuasan wisatawan serta berdampak positif terhadap ekonomi, kesejahteraan sosial, dan kelestarian lingkungan serta budaya di suatu kawasan wisata.

Adapun faktor-faktor yang mempengaruhi pengembangan SDM terdiri atas faktor internal dan faktor eksternal. Faktor internal meliputi visi, misi, tujuan, strategi pencapaian tujuan, sifat dan jenis kegiatan, dan jenis teknologi yang digunakan. Faktor eksternal meliputi kebijaksanaan pemerintah, sosio-budaya masyarakat, dan perkembangan iptek (Wijatno, 2009).

Langkah-langkah pengembangan SDM menurut Rachmawati (2010) dan Siagian (2010) meliputi (1) mengidentifikasi kebutuhan, (2) menentukan tujuan program pengembangan, (3) merencanakan dan mengembangkan program pengembangan SDM, (4) mengimplementasi program, (5) mengidentifikasi manfaat, dan (6) mengevaluasi dan monitoring program.

Dosen adalah guru pada lembaga pendidikan tinggi (Tampubolon, 2001). Menurut Undang-Undang Guru dan Dosen Nomor 14 Tahun 2005, dosen di perguruan tinggi merupakan tenaga profesional. Pasal 1, Butir 1 menegaskan bahwa dosen adalah pendidik profesional dan ilmuwan dengan tugas mentransformasikan, mengembangkan, dan menyebarluaskan ilmu pengetahuan, teknologi, dan seni, melalui pendidikan, penelitian, dan pengabdian kepada masyarakat.

$\begin{array}{ccc}\text { Seorang } & \text { dosen dituntut memiliki } \\ \text { kompetensi } & \text { tinggi } & \text { sehingga dapat }\end{array}$ mewujudkan standar kinerja mutu, yang selanjutnya akan bermuara pada peningkatan mutu perguruan tinggi sekaligus berdampak pada mutu lulusannya. Kompetensi dosen dapat terbentuk melalui lima karakter yaitu: watak, motif, konsep diri, pengetahuan, dan keterampilan (Sumardjoko, 2010). 
Menurut Jero Wacik (2008), dosen di lembaga pendidikan tinggi pariwisata selain dituntut untuk memiliki keahlian profesi dosen secara umum, juga dituntut memiliki pengalaman dan keahlian tambahan selain pendidikan formal. Pengalaman dan keahlian dosen bisa diperoleh melalui beberapa cara, diantaranya, melalui pendidikan formal (studi lanjut S2 dan S3), memperluas jaringan komunikasi-informasi serta ideide dengan pihak terkait; membiasakan diri dengan suasana hospitality, dan menguasai teknologi informatika karena tuntutan era globalisasi.

Dalam klausul 6.1, IWA 2:2007-ISO 9001:2000 disebutkan bahwa pimpinan perguruan tinggi berkewajiban mengelola dan mengembangkan dosen karena dosen memiliki peran yang sangat strategis dan sebagai penopang utama dalam meningkatkan mutu pendidikan di PTnya. Sebagai konsekuensinya, sebuah lembaga pendidikan tinggi dituntut untuk menyediakan, mengelola, dan mengembangkan dosen lebih selektif sehingga mampu menghadapi tantangan dan tuntutan yang bersifat kompetitif dan berimplikasi pada munculnya comparative advantage terhadap suatu eksistensi lembaga pendidikan di tengah-tengah masyarakat.

Lebih lanjut Bambang Parikesit (2009) mengutarakan bahwa pengembangan dosen dapat dilihat dalam konteks sebagai berikut.

1. Bagaimana sistem perekrutan dosen

2. Bagaimana membentuk pola perspsi antara kualitas kognitif dosen dengan kemampuan beradaptasi dosen pada kultur dan sistem akademis yang diterapkan di lembaga agar tidak terjadi distorsi komunikasi.

3. Bagaimana mekanisme kontrol yang diterapkan oleh perguruan tinggi terhadap proses belajar-mengajar yang dilaksanakan dosen.

4. Bagaimana penghargaan (reward) yang diberikan oleh perguruan tinggi kepada para dosen yang telah memberikan konstruksi positif bagi eksistensi institusi perguruan tinggi itu sendiri.

Salah satu tantangan penting yang dihadapi lembaga pendidikan tinggi adalah bagaimana mengelola sebuah mutu/ kualitas. Agar mutu tetap terjaga dan agar proses peningkatan mutu tetap terkontrol maka harus ada standar yang diatur dan disepakati untuk dijadikan indikator evaluasi keberhasilan peningkatan mutu tersebut (ada bencmarking/titik acuan standar/ patokan). Dalam manajemen mutu, menurut Tampubolon (2001) terdapat tiga sistem yang berkembang yaitu Pengawasan Mutu (PM), Penjaminan Mutu/Jaminan Mutu (JM), dan Manajemen Mutu Terpadu (MMT).

Sumardjoko (2010) menambahkan bahwa perguruan tinggi dapat mengembangkan model sistem standar mutu ISO-9000 dalam hal (1) pengelolaan dan pengembangan dosen; (2) pengembangan kurikulum dan materi kuliah; dan (3) peningkatan pengendalian proses akademik.

Penelitian yang relevan dengan penelitian ini di antaranya "Manajemen Pengembangan SDM di Perguruan Tinggi Muhammadiyah Purwokerto" (Siska Setyawati, 2006); "Pengembangan SDM di UII" (Muhamad Yazid:2008); "Manajemen Pengembangan SDM di Sekolah Tinggi Agama Kristen Sentani, Jayapura" (Evelien Fitri Ugadje:2009).

\section{METODE PENELITIAN}

Penelitian ini menggunakan pendekatan kualitatif dengan teknik pengumpulan data yang meliputi observasi, wawancara, dan dokumentasi. Keabsahan data dilakukan secara triangulasi. Adapun pengambilan sampel sumber data dilakukan secara purposive dan snowbaal.

Analisis data yang dilakukan bersifat induktif/kualitatif berdasarkan fakta-fakta 
yang ditemukan di lapangan dan kemudian dikonstruksikan menjadi hipotesis atau teori. Metode kualitatif digunakan untuk mendapatkan data yang mendalam, suatu data yang mengandung makna. Makna adalah data yang sebenarnya, data yang pasti yang merupakan suatu nilai di balik data yang tampak.

\section{HASIL PENELITIAN DAN PEMBAHASAN}

\section{Perencanaan Dosen}

Dalam usianya yang ke-25 tahun, Sekolah Tinggi Pariwisata AMPTA Yogyakarta tentu sudah mempunyai perencanaan dosen. Apalagi, menurut beberapa narasumber, lulusan STP AMPTA banyak yang diterima menjadi karyawan di industri pariwisata, seperti hotel dan agen perjalanan wisata. Selain itu, banyak lulusan Sekolah Tinggi Pariwisata AMPTA Yogyakarta yang berwirausaha di restoran, laundry, usaha boga, dll.

Menurut Ketua Sekolah Tinggi Pariwisata AMPTA Yogyakarta, melihat persyaratan formal seorang dosen (memiliki jabatan akademik / minimal asisten ahli, minimal S2, lulus sertifikasi, dan melaksanakan tridharma perguruan tinggi secara proporsional), maka dosen Sekolah Tinggi Pariwisata AMPTA Yogyakarta yang mempunyai tugas dan tanggung jawab mencetak lulusan bermutu perlu direncanakan. Namun, saat ini Sekolah Tinggi Pariwisata AMPTA Yogyakarta belum melaksanakan perencanaan dosen dengan maksimal.

Saat ini, Sekolah Tinggi Pariwisata AMPTA Yogyakarta tengah melakukan restrukturisasi organisasi dengan mencari pola yang tepat untuk merancang perencanaan program pengembangan SDM Sekolah Tinggi Pariwisata AMPTA Yogyakarta.
Pendokumentasian Renstra Perencanaan SDM juga tengah diupayakan pelaksanaannya. Sebagaimana diketahui pendokumentasian Perencanaan Pengembangan SDM Sekolah Tinggi Pariwisata AMPTA Yogyakarta merupakan upaya menuju ke penjaminan mutu. Perencanaan dosen Sekolah Tinggi Pariwisata AMPTA Yogyakarta akan dilaksanakan secara bertahap/step by step sesuai dengan skala prioritas, berdasarkan kebutuhan dan formasi rasio kebutuhan dosen dan jumlah mahasiswa, serta ketersediaan anggaran. Perencanaan dosen nantinya akan dilaksanakan di bawah senat/ lembaga disesuaikan dengan peraturan yang berlaku, Undang-Undang Dosen, serta Standar Pendidikan Nasional.

Meskipun perencanaan SDM merupakan sebuah keharusan dalam setiap organisasi, menurut Pembantu Ketua I Sekolah Tinggi Pariwisata AMPTA Yogyakarta, lembaga memandang belum saatnya melakukan perencanaan dosen dengan beberapa alasan (seperti yang disampaikan di atas). Namun, untuk Sekolah Tinggi Pariwisata AMPTA Yogyakarta saat ini, yang lebih penting lagi adalah mempersiapkan SDM yang memiliki kualifikasi di bidang SDM sehingga perencanaan dosen bisa dipersiapkan secara sistematis. Dengan perencanaan yang sistematis tersebut akan memudahkan pelaksanaan, evaluasi, dan pengembangannya.

Sebagai lembaga yang berada di bawah yayasan, tidak mudah mengubah budaya/model kepemimpinan yang berada di bawah Yayasan Pendidikan Karya Sejahtera sebelumnya. Maka saat ini, Sekolah Tinggi Pariwisata AMPTA Yogyakarta tengah berbenah menuju ke perguruan tinggi yang berkualitas, yaitu dengan menertibkan budaya organisasi, diantaranya adalah perencanaan dosen Sekolah Tinggi Pariwisata AMPTA 
Yogyakarta yang meliputi rekrutmen, seleksi, dan orientasi.

Rekrutmen dosen menurut Wakil Ketua III dilakukan berdasarkan kebutuhan. Bahkan, bisa dikatakan rekrutmen dosen belum tertib karena masih mendahulukan rasa kebersamaan/ paguyuban. Meskipun pernah merekrut dosen melalui pengumuman/iklan, referensiorang dalam, dan relasi, Sekolah Tinggi Pariwisata AMPTA Yogyakarta cenderung melaksanakan rekrutmen dosen melalui referensi orang dalam. Rekrutmen dosen dari rekomendasi orang dalam yang telah lama bekerja di Sekolah Tinggi Pariwisata AMPTA Yogyakarta dianggap memberikan 'garansi' karakter dan kompetensi calon dosen yang bersangkutan. Di samping itu, rekrutmen juga memprioritaskan dosen tidak tetap dengan dua alasan. Pertama, dosen tersebut sudah lama mengabdi di Sekolah Tinggi Pariwisata AMPTA Yogyakarta sehingga sudah diketahui kinerja dan karakternya. Kedua, alasan untuk memotivasi dosen agar memiliki komitmen dan konsisten dalam menjalankan tugas profesinya.

Sementara itu, Seleksi dosen Sekolah Tinggi Pariwisata AMPTA Yogyakarta untuk sepuluh terakhir ini tidak dilakukan. Hal itu karena melihat kenyataan bahwa lembaga belum membutuhkan penyeleksian dosen karena jumlah mahasiswa cenderung menurun sehingga dengan jumlah dosen yang ada dirasa sudah cukup.

Meskipun demikian, Sekolah Tinggi Pariwisata AMPTA Yogyakarta saat booming yaitu sebelum reformasi, pernah melaksanakan seleksi bagi calon dosen. Penyeleksian tersebut meliputi 1) tes kualifikasi dengan standar terpenuhi, 2) tes akademik, 3) psikotes, 4) tes wawancara.

Saat ini lembaga sangat open dalam rangka merancang seperangkat konsep kriteria dosen yang dijadikan persyaratan dalam perekrutan dan seleksi dosen tetap Sekolah Tinggi Pariwisata AMPTA Yogyakarta di masa yang akan datang. Konsep tersebut selanjutnya akan didokumentasikan dan disosialisasikan sehingga bisa dijadikan pedoman dalam rekrutmen dan seleksi SDM Sekolah Tinggi Pariwisata AMPTA Yogyakarta pada umumnya, dan dosen tetap Sekolah Tinggi Pariwisata AMPTA Yogyakarta pada khususnya. Adapun kriteria yang dimaksud adalah sebagai berikut.

a. Dosen tidak tetap sudah mengabdi minimal satu tahun.

b. Minimal S2, diutamakan keahlian pariwisata atau sesuai dengan keahlian yang dibutuhkan. Dosen mata kuliah umum diberi pelatihan tentang kepariwisataan.

c. Praktisi pariwisata/perhotelan dengan pengalaman kerja cukup lama.

d. Memiliki loyalitas, kepedulian, komitmen, dan konsisten pada lembaga untuk mewujudkan visi, misi, dan tujuan lembaga.

e. Memiliki performance sesuai dengan karakter insan pariwisata: diutamakan yang masih muda, energik, berpenampilan menarik, disiplin, tegas, kreatif, inovatif, dan santun.

f. Lulus tes tertulis, tes wawancara, dan tes profesi, lalu diajukan ke Yayasan dan dietujui oleh senat.

Untuk Orientasi bagi calon pegawai baru (dosen) Sekolah Tinggi Pariwisata AMPTA Yogyakarta, Ketua Sekolah Tinggi Pariwisata AMPTA Yogyakarta menjelaskan bahwa orientasi dosen tidak harus selalu diartikan secara mekanis saja. Oleh karena itu, yang bersangkutan dilibatkan secara 
langsung dalam berbagai kegiatan manajerial, selain juga kegiatan keluar (industri pariwisata). Hal itu selain mempersiapkan dosen langsung berintegrasi dengan segenap sivitas akademika dalam kegiatan akademik dan nonakademik, juga melibatkan dosen berinteraksi dengan lingkungan kerja.

\section{Pengembangan Dosen Sekolah Tinggi Pariwisata AMPTA Yogyakarta}

\section{a. Pelaksanaan Pengembangan Dosen Sekolah Tinggi Pariwisata AMPTA Yogyakarta}

Pengembangan dosen Sekolah Tinggi Pariwisata AMPTA Yogyakarta secara struktur organisasi berada di bawah koordinasi, tugas, dan tanggung jawab Pembantu Ketua I Bidang Akademik. Pembantu Ketua I berfungsi sebagai penyelenggaraan proses akademik dan pengelolaan pengembangan Dosen. Sekolah Tinggi Pariwisata AMPTA Yogyakarta saat ini tengah membenahi pelaksanaan pengembangan Dosen Sekolah Tinggi Pariwisata AMPTA Yogyakarta. Pengembangan dosen dimulai dengan sosialisasi adanya undang-undang yang berlaku bahwa dosen harus berlatar belakang S-2 dan dituntut meningkatkan jenjang karier jabatan akademik.

Dalam pelaksanaan pengembangan dosen Sekolah Tinggi Pariwisata AMPTA Yogyakarta terdapat dilema yang dihadapi. Ketua Sekolah Tinggi Pariwisata AMPTA Yogyakarta mengatakan sebagai berikut. Beberapa dosen Sekolah Tinggi Pariwisata AMPTA Yogyakarta berlatar belakang praktisi yaitu mantan karyawan atau manajer hotel berbintang. Secara keahlian dan keterampilan kompetensi mereka tidak diragukan lagi, tetapi secara akademisi mereka tidak memenuhi kriteria dosen. Lalu ada tanda tanya, apakah seorang lulusan S-2 sudah menjamin skill-nya lebih baik daripada praktisi yang berlatar belakang pendidikan vokasi. Maka ketika ada berita bahwa nantinya akan ada penyetaraan S-1 atau S-2 bagi dosen yang berlatar belakang praktisi atau pendidikan vokasi. Maka ini hal yang menggembirakan meskipun baru wacana.

Pelaksanaan pengembangang dosen Sekolah Tinggi Pariwisata AMPTA Yogyakarta untuk saat ini, menurut Pembantu Ketua I, belum terlaksana dengan baik karena beberapa faktor: keterbatasan dana, kurangnya motivasi dari dosen terhadap pencapaian proses jabatan akademik, dan pengembangan dosen Sekolah Tinggi Pariwisata AMPTA Yogyakarta bersifat kondisional-situasional. Namun demikian, Sekolah Tinggi Pariwisata AMPTA Yogyakarta telah melaksanakan pengembangan dosen secara formal sebagaimana berikut ini.

a. Peningkatan jabatan akademik sesuai dengan aturan yang berlaku dengan tetap berpedoman pada pelaksanaan Tridharma Perguruan Tinggi secara konsisten.

b. Memfasilitasi studi lanjut S-2 dan S-3 secara berkesinambungan dan merata, dan penyetaraan S-2 bagi dosen praktisi (dalam wacana).

c. Sosialisasi dan motivasi kepada para dosen tentang UU Dosen 
dan sertifikasi dosen.

d. Menyiapkan

Renstra

Pengembangan Dosen, baik dalam pengajaran, penelitian, maupun pengabdian pada masyarakat agar bisa memenuhi persyaratan jabatan fungsional dan sertifikasi dosen.

e. Memfasilitasi seminar, diskusi, simposium, workshop tentang kurikulum, pendidikan dan pengajaran serta tentang penelitian ilmiah, baik yang dilaksanakan di lingkungan Sekolah Tinggi Pariwisata AMPTA Yogyakarta maupun di luar Sekolah Tinggi Pariwisata AMPTA Yogyakarta secara merata.

f. Memotivasi dan memfasilitasi penelitian ilmiah dan mempublikasikannya dalam jurnal ilmiah yang terakreditasi.

g. Memotivasi dan memfasilitasi pelaksanaan Tridhrama Perguruan Tinggi bagi para dosen Sekolah Tinggi Pariwisata AMPTA Yogyakarta secara merata, terus-menerus, dan berkesinambungan.

h. Merencanakan pemberian reward bagi dosen yang berprestasi.

i. Merencanakan dan memfasilitasi pengembangan dosen dengan pembekalan ilmu pariwisata bagi dosen yang berlatar belakang ilmu murni sehingga visi, misi, dan tujuan Sekolah Tinggi Pariwisata AMPTA Yogyakarta dapat terwujud.

j. Memfasilitasi dosen Sekolah Tinggi Pariwisata AMPTA Yogyakarta menjadi asesor uji kompetensi.

$\mathrm{k}$. Mendatangkan guest lecture dari praktisi ke kampus untuk kuliah praktik bagi para dosen yang mengampu kuliah praktik.

Adapun pengembangan dosen Sekolah Tinggi Pariwisata AMPTA Yogyakarta secara nonformal adalah sebagai berikut.

a. Peningkatan produktivitas kerja, baik secara individual maupun antar sivitas akademika yang secara bersama-sama mencapai sasaran dan tujuan lembaga yang telah ditetapkan.

b. Terwujudnya hubungan timbal balik yang harmonis dan komunikasi organisasi secara efektif antara pimpinan dengan segenap sivitas akademika sehingga koordinasi, pendelegasian wewenang, proses pengambilan keputusan dan interaksi bisa terjalin secara proporsional, serta terciptanya sikap saling menghargai.

c. Mendorong terciptanya keterbukaan manajemen dengan gaya keteladanan dan manajerial yang partisipatif.

d. Penyelesaian konflik secara fungsional sehingga berdampak pada tumbuhnya rasa persatuan dan kekeluargaan oleh sivitas akademika pada lembaga tersebut.

e. Menambah wawasan dosen untuk mengembangkan kualitas bahan ajarnya, model dan variasi mengajar, substansi materi ajarnya sehingga materi yang disampaikan kepada mahasiswa selalu up to date.

f. Memperluas hubungan 
kemitraan, presentasi ilmiah, dan jelajah objek wisata dengan dosen lain, baik di perguruan tinggi pariwisata, perguruan tinggi umum, para praktisi pariwisata maupun para pelaku industri pariwisata..

g. Memotivasi dosen untuk lebih aktif daripada mahasiswa, baik belajar maupun dalam mengakses informasi, terutama yang berkaitan dengan kepariwisataan sehingga ketika nanti berada di dunia kerja mereka tidak canggung untuk melakukan pekerjaannya.

\section{b. Penilaian}

Penilaian terhadap efektifiats program pengembangan dosen Sekolah Tinggi Pariwisata AMPTA Yogyakarta belum tertata dengan sistematis sehingga belum bisa terukur secara signifikan. Hal itu sesuai dengan penuturan Ketua Sekolah Tinggi Pariwisata AMPTA Yogyakarta bahwa semua pelaksanaan program pengembangan SDM sebaiknya dievaluasi. Dengan evaluasi, perencanaan dan pelaksanaan program pengembangan SDM Sekolah Tinggi Pariwisata AMPTA Yogyakarta akan mudah untuk diukur. Dengan begitu bahan evaluasi tersebut bisa dijadikan masukan untuk peningkatan SDM Sekolah Tinggi Pariwisata AMPTA Yogyakarta dalam rangka menjamin mutu Sekolah Tinggi Pariwisata AMPTA Yogyakarta . Namun, yang terjadi di Sekolah Tinggi Pariwisata AMPTA Yogyakarta, evaluasi terhadap pengembangan SDM belum terdokumentasi dan belum terformat dengan sistematis.
Program pengembangan SDM Sekolah Tinggi Pariwisata AMPTA Yogyakarta selama ini terlaksana tanpa ada evaluasi. Ketua Sekolah Tinggi Pariwisata AMPTA Yogyakarta mengatakan bahwa program pengembangan SDM Sekolah Tinggi Pariwisata AMPTA Yogyakarta selama ini hanya dilaksanakan tanpa ada evaluasi. Hal itu disebabkan oleh pengaruh budaya lama yang sudah terkondisi demikian. Maka saat ini, Sekolah Tinggi Pariwisata AMPTA Yogyakarta tengah memformat penilaian kinerja dosen sesuai dengan standar Sekolah Tinggi Pariwisata AMPTA Yogyakarta sebagai perguruan tinggi vokasi. Selanjutnya standar penilaian tersebut akan disosialisasikan, dilaksanakan, dan ditindaklanjuti.

Meskipun demikian, ada beberapa dosen yang secara mandiri sudah menyiapkan format penilaian kinerja dosen yang diberikan kepada mahasiswa. Kriteria penilaian dosen Sekolah Tinggi Pariwisata AMPTA Yogyakarta meliputi kedisiplinan, kelengkapan administrasi, pelaksanaan Tridharma Perguruan Tinggi, serta ada umpan balik dari mahasiswa, rekan sejawat, karyawan, dan pimpinan.

Adapun manfaat penilaian kinerja dosen menurut Pembantu Ketua III Sekolah Tinggi Pariwisata AMPTA Yogyakarta , "dapat memotivasi dosen untuk meningkatkan kinerjanya, baik dalam proses belajar-mengajar, penelitian, dan pengabdian kepada masyarakat. Selain itu, dengan adanya umpan balik dari rekan sejawat diharapkan dosen senior memberikan arahan kepada dosen yunior demi 
terwujudnya optimalisasi kinerja dosen Sekolah Tinggi Pariwisata AMPTA Yogyakarta ."

\section{Profesionalisme Dosen Sekolah Tinggi Pariwisata AMPTA Yogyakarta}

\section{a. Peran Dosen dalam Pendidik-an dan Pengajaran}

Dalam proses pembelajaran di Sekolah Tinggi Pariwisata AMPTA Yogyakarta, dosen menduduki peran utama. Artinya, tingkat keberhasilan pembelajaran sangat ditentukan oleh sejauh mana dosen melaksanakan tugas dan tanggung jawabnya. Oleh karena itu, tidak mengherankan apabila para stakeholders memperhatikan bahwa salah satu indikator mutu sebuah pendidikan tinggi itu terarah kepada mutu dosennya. Adapun tugas Dosen Sekolah Tinggi Pariwisata AMPTA Yogyakarta dalam pendidikan dan pengajaran adalah sebagai berikut.

\section{b. Tugas Dosen yang Berkaitan dengan Mahasiswa}

Tugas dosen yang berkaitan dengan mahasiswa adalah sebagai fasilitator dan motivator bagi mahasiswa. Tugas dosen Sekolah Tinggi Pariwisata AMPTA Yogyakarta sangat berpengaruh terhadap pembentukan kepribadian, sikap, dan pemikiran mahasiswa. Oleh karea itu, menurut Pembantu Ketua I "dosen hendaknya senantiasa menjadi teladan bagi mahasiswa dalam hal kedisiplinan, berkepribadian yang baik, berpenampilan rapi, santun dalam bersosialisasi dengan segenap sivitas akademika, tidak merokok di sembarang tempat atau di ruang kuliah, berjiwa religius, dan berakhlak mulia.

Selain memiliki kemampuan akademik, intelektual, dan etika profesi, dosen juga harus dapat menempatkan mahasiswa sebagai subjek pembelajaran. Dosen tidak hanya memberikan materi kuliah, tetapi juga memberikan bimbingan akademik, bimbingan tugas akhir, dan bimbingan konseling. Dengan demikian, interaksi dosen-mahasiswa Sekolah Tinggi Pariwisata AMPTA Yogyakarta bisa terjalin dengan baik, sebagaimana yang dikatakan Pembantu Ketua III.

Pimpinan selalu memotivasi dosen Sekolah Tinggi Pariwisata AMPTA Yogyakarta agar bisa melaksanakan tugasnya secara maksimal dan lebih kreatif sehingga input yang 'paspasan' bisa diproses menjadi lulusan yang kompetitif. Atau pimpinan Sekolah Tinggi Pariwisata AMPTA Yogyakarta mengibaratkan tugas dosen Sekolah Tinggi Pariwisata AMPTA Yogyakarta seperti "mengasah batu sungai menjadi batu pualam".

\section{c. Tugas Dosen yang Berkaitan dengan Profesi}

Sebagai tuntutan profesi, dosen Sekolah Tinggi Pariwisata AMPTA Yogyakarta diharapkan bisa meningkatkan efektifitas pembelajaran dengan aktif dan kreatif mencari metode pembelajaran terbaru dan metode yang paling tepat guna menunjang tercapainya tujuan pembelajaran mata kuliah yang diajarkan kepada mahasiswa, misalnya dengan metode pembelajaran PAIKEM (Pembelajaran aktif, inovatif, kreatif, efektif, dan menyenangkan). Selain itu, metode penilaian 
mahasiswa pun perlu dievaluasi dan diperbaiki. Tugas yang diberikan kepada mahasiswa juga hendaknya mendapat umpan balik dari dosen yang bersangkutan.

Dosen Sekolah Tinggi Pariwisata AMPTA Yogyakarta juga diharapkan bisa meningkatkan kualitas profesinya dengan mengembangkan ilmu pengetahuan disiplin bidang ilmunya dengan melaksanakan penelitian, membuat tulisan untuk dipublikasikan, serta aktif menyajikan makalah dalam acara diskusi ilmiah, pengembangan kurikulum, dan keikutsertaan pada kegiatan ilmiah lainnya, baik yang diselenggarakan lembaga, mahasiswa, maupun pihak lain.

Hal yang tak kalah penting dalam profesi dosen adalah pengabdian kepada masyarakat. Pengabdian kepada masyarakat perlu ditumbuhkembangkan agar tidak terjadi ketimpangan dalam melakukan tugas dan fungsinya di tengah-tengah masyarakat. Hal itu juga sekaligus sebagai salah satu upaya untuk mencegah terisolirnya Sekolah Tinggi Pariwisata AMPTA Yogyakarta dari masyarakat. Maka dosen Sekolah Tinggi Pariwisata AMPTA Yogyakarta dituntut untuk peka terhadap persoalan dan kebutuhan masyarakat. Selain itu, dosen Sekolah Tinggi Pariwisata AMPTA Yogyakarta juga dituntut untuk aktif, kreatif, dan inovatif dalam memberdayakan masyarakat untuk meningkatkan kehidupan masyarakat. Dalam hal ini, dosen hendaknya juga melibatkan mahasiswa.

\section{d. Tugas Dosen yang Berkaitan dengan Institusi}

Sebagai ujung tombak perbaikan mutu di Sekolah Tinggi Pariwisata AMPTA Yogyakarta , dosen Sekolah Tinggi Pariwisata AMPTA Yogyakarta dituntut untuk memiliki komitmen, konsisten, dan kerja sama yang kompak dalam pengembangan Sekolah Tinggi Pariwisata AMPTA Yogyakarta menuju perguruan tinggi yang bermutu sesuai dengan visi, misi, dan tujuan Sekolah Tinggi Pariwisata AMPTA Yogyakarta . Selain itu, dosen Sekolah Tinggi Pariwisata AMPTA Yogyakarta senantiasa memberikan dukungan yang baik dan bertartisipasi aktif terhadap semua kegiatan lembaga serta tetap menjaga nama baik lembaga di manapun berada.

\section{e. Peran Dosen dalam Penelitian}

Peran dosen Sekolah Tinggi Pariwisata AMPTA Yogyakarta dalam penelitian yang berada di bawah LP3M, selain melaksanakan penelitian individual maupun penelitian kelompok adalah melaksanakan hal-hal sebagai berikut.

- Sebagai nara sumber/pemakalah dalam diskusi dan seminar ilmiah, baik yang diadakan secara rutin di Sekolah Tinggi Pariwisata AMPTA Yogyakarta maupun yang diselenggarakan secara periodik oleh pihak luar.

- Sebagai penulis buku ajar mata kuliah.

- Sebagai penerjemah buku ajar matakuliah berbahasa asing ke dalam bahasa Indonesia.

- Sebagai penulis artikel ilmiah dalam jurnal ilmiah, baik yang diterbitkan oleh Sekolah Tinggi Pariwisata AMPTA Yogyakarta yaitu Jurnal Ilmiah 
Media Wisata dengan ISSN 1693-5969 maupun perguruan tinggi lain, baik lokal maupun nasional. Obsesinya, ke depan diharapkan ada hasil penelitian dosen Sekolah Tinggi Pariwisata AMPTA Yogyakarta yang bisa menembus jurnal internasional.

- Sebagai peserta Pelatihan Penyusunan Proposal dan Research di UGM dan di perguruan tinggi lain.

\section{f. Peran Dosen dalam Pengabdian kepada Masyarakat}

Melalui LP3M, program-program pengabdian pada masyarakat yang dilaksanakan di Sekolah Tinggi Pariwisata AMPTA Yogyakarta adalah sebagai berikut.

- Pelayanan Kepada Masya-rakat

- Kerja Sama (dalam negeri dan luar negeri)

• Desa Binaan

• Kuliah Kerja Nyata (KKN)

• Relawan Kemanusiaan

\section{Sekolah Tinggi Pariwisata AMPTA Yogyakarta Menuju Penjaminan Mutu}

Sebagaimana telah diuraikan di atas bahwa sampai saat ini Sekolah Tinggi Pariwisata AMPTA Yogyakarta belum menerapkan penjaminan mutu secara optimal. Yang dilakukan lembaga saat ini adalah menata ulang organisasi pendidikan tinggi melalui faktor internal. Saat ini, Sekolah Tinggi Pariwisata AMPTA Yogyakarta tengah merintis terbentuknya Tim Penjaminan Mutu Sekolah Tinggi Pariwisata AMPTA Yogyakarta dan Tim Pemantau Jabatan Struktural Dosen Sekolah Tinggi Pariwisata AMPTA Yogyakarta
. Untuk menuju mutu akademik perlu dirumuskan berbagai kebijakan dan program-program strategis melalui penyusunan Standrad Operating Procedure (SOP) sesuai dengan standar Sekolah Tinggi Pariwisata AMPTA Yogyakarta .

Selain pembenahan faktor internal, Sekolah Tinggi Pariwisata AMPTA Yogyakarta juga terus berupaya meningkatan kerja sama dengan pihak luar, baik lembaga pendidikan menengah atas/SMK Pariwisata, lembaga pendidikan tinggi, pihak industri pariwisata, pemerintah, swasta, dan pihak-pihak lain yang berkompeten dengan lulusan Sekolah Tinggi Pariwisata AMPTA Yogyakarta - Bahkan, saat ini Sekolah Tingi Pariwisata Trisakti Jakarta yang telah membuka Prodi S2 Pariwisata memberikan penawaran beasiswa bagi sivitas akademika Sekolah Tinggi Pariwisata AMPTA Yogyakarta untuk melanjutkan studi dengan konsentrasi/ kualifikasi pariwisata.

Ada beberapa unsur organisasi yang tengah dibenahi oleh pimpinan Sekolah Tinggi Pariwisata AMPTA Yogyakarta beserta jajarannya meliputi hal-hal sebagai berikut.

a. Pembenahan sistem manajemen, salah satunya melalui Draft Standar

b. Akademik Sekolah Tinggi Pariwisata AMPTA Yogyakarta yang merupakan penjabaran dari Kebijakan Akademik dan disusun oleh Senat Akademik 2010.

c. Pembudayaan iklim komunikasi efektif dengan melepas benang ruwet' sistem yang sudah ada untuk dikomunikasikan secara optimal pada segenap sivitas akademika.

d. Pembudayaan suasana akademik dan iklim organisasi kondusif 
dari aspek soft meliputi: kualitas kepemimpinan, kadar kepercayaan, komunikasi ke atas dan ke bawah, tanggung jawab dalam pekerjaan, pembudayaan akses e-jurnal, dan rintisan penerimaan mahasiswa baru secara online.

e. Penertiban proses akademik diawali dengan redesain kurikulum berbasis kompetensi dan karakter secara integrited melalui RPKPS/ SAP, silabus, dan GBPP.

Pengembangan dosen dalam rangka meningkatkan mutu Sekolah Tinggi Pariwisata AMPTA Yogyakarta meliputi : Pertama, pengembangan kompetensi pedagogik, kepribadian, profesional, dan sosial. Kedua, pengembangan keteladanan disiplin kerja. Ketiga, pengembangan motivasi kerja. Keempat, pengembangan prestasi kerja. Kelima, pengembangan karier dan kesejahteraan. Keenam, pengembangan kinerja dosen, Ketujuh, pengembangan profesi dosen, Kedelapan, pengembangan networking dengan pihak terkait.

Pengembangkan dosen sebagai upaya meningkatkan mutu Sekolah Tinggi Pariwisata AMPTA Yogyakarta, yang selama ini dilakukan oleh lembaga adalah dengan terus berusaha untuk meningkatkan karier dosen melalui halhal sebagai berikut.

a. Studi lanjut karier pendidikan S-1, S-2, dan S-3.

b. Berpartisipasi aktif dalam penulisan karyailmiah monumental, penulisan buku referensi, dan penulisan ilmiah pada jurnal terakreditasi.

c. Aktif dalam kegiatan Tridharma Perguruan Tinggi.

d. Aktif dalam forum-forum ilmiah, seperti diskusi, seminar, dan simposium. e. Aktif mengikuti lokakarya, pelatihan, workshop untuk menunjang pengembangan profesi dosen, baik untuk pembelajaran, penelitian, maupun pengabdian kepada masyarakat.

f. Aktif mengikuti sosialisasi UU Dosen, sertifikasi dosen, dan karier jabatan akademik secara merata.

g. Aktif menjalin hubungan ilmiah dengan para dosen dari perguruan tinggi lain serta dengan industri pariwisata.

h. Aktif meningkatkan peran dosen sebagai tim asesor.

i. Aktif dan kreatif mengintegrasi-kan mata kuliah yang diampu dengan mata kuliah lain yang menunjang sehingga nilai dan karakteristik pariwisata sebagai ciri khas Sekolah Tinggi Pariwisata AMPTA Yogyakarta bisa terasakan pada setiap mata kuliah yang diajarkan di Sekolah Tinggi Pariwisata AMPTA Yogyakarta .

\section{KESIMPULAN}

Sekolah Tinggi Pariwisata AMPTA Yogyakarta yang telah berusia 25 tahun tengah berbenah menuju pejaminan mutu. Mutu dalam produk perguruan tinggi tidak mungkin terjadi tanpa mutu dalam proses. Mutu dalam proses pendidikan membutuhkan komitmen yang kuat dari segenap sivitas akademika, terutama dosen. Dosen Sekolah Tinggi Pariwisata AMPTA Yogyakarta akan dapat meningkatkan mutu Sekolah Tinggi Pariwisata AMPTA Yogyakarta apabila dosen tersebut memiliki kompetensi pedagogik, kompetensi kepribadian, kompetensi profesional, dan kompetensi sosial. Semakin baik kompetensi dosen semakin profesional dalam melaksanakan tugasnya. Peran utama dosen adalah menjalankan tugas pendidikan, penelitian, 
dan pengabdian kepada masyarakat secara proporsional. Dosen dikatakan bermutu apabila mampu menunjukkan peran dan kinerjanya secara maksimal. Dosen dikatakan mampu menunjukkan peran atau kinerjanya secara maksimal apabila dosen mampu berperilaku sesuai dengan yang diharapkan. Dalam rangka meningkatkan mutu dosen, Sekolah Tinggi Pariwisata AMPTA Yogyakarta tengah merintis manajemen pengembangan dosen, baik secara formal maupun nonformal.

\section{DAFTAR PUSTAKA}

Hasibuan, Malayu S. 2001. Manajemen Sumber Daya Manusia. Cetakan Ketiga. Jakarta: Bumi Aksara.

http://caretourism. wordpress. com $/ 2009 / 02 / 25 /$ sertifikasisdm-pariwisata-kebutuhanmendesak/. Diakses 5 Agustus 2011.

http://pr2.umm.ac.id/files/file/data/ manajemen-sdm-umm/pdf. Diakses 15 Sepetember 2011.

http://optimalisasi-sumberdaya-dosen-html. Diakses 5 Agustus 2011.

Jones, James J. and Donald L. Walters. 2008. Human Resource Management in Education. Yogyakarta: Q-Media.

Kesit, B. 2009. Peningkatan Mutu Pendidikan. dikutip dari http://bambangkesit. Staff. ui i.ac.id/2009/03/.../ manajemen-sdm-dosendalam-meningkatkan-mutupendidikan-di-perguruan...$29 \mathrm{k}$ - diakses tanggal 22 November 2010.

Laporan Akhir Strategi Pengembangan SDM Bidang Kebudayaan, Pariwisata, Pemuda, dan
Olahraga. 2009. Direktorat Kebudayaan, Pariwisata, Pemuda, dan Olahraga. Deputi Bidang SDM dan Kebudayaan. Badan Perencnaan Pembangunan Nasional.

Mathis, Robert L and John H Jackson. 2002. Human Resource Management. Penerjemah Jimmy Sadeli dan Bayu Prawira Hie. Jakarta: Salemba Empat.

Mulyono. 2008. Manajemen Administrasi dan Organisasi Pendidikan. Yogyakarta: Ar-Ruzz Media.

Notoatmodjo, $\quad$ Soekidjo. 2009. Pengembangan Sumber Daya Manusia. Jakarta: Rineka Cipta.

Panduan Penyusunan Rencana Pengembangan Dosen PTS. 2010. Direktorat Ketenagaan Direktorat Jenderal Pendidikan Tinggi Kementerian Pendidikan Nasional.

Pedoman Beban Kerja Dosen dan Evaluasi Pelaksanaan Tridharma Perguruan Tinggi. 2011. Kementerian Pendidikan Nasional. Biro Kepegawaian. Jakarta.

Putri, Sevie Istiana dan Hujair A.H.S. 2010. "Manajemen Pendidikan Tinggi Berbasis pada Total Quality Manajemen." Dalam htttp://manajemen-mutupendidikan-sevie-dan-hujair. pdf//diakses 10 November 2010 .

Rachmawati, Ike Kusdiyah. 2008. Manajemen Sumber Daya Manusia. Yogyakarta: Penerbit ANDI.

Sallis, Edward. 2010. Total Quality Management in Education: 
Manajemen Mutu Pendidikan.

Cetakan IX. Diterjemahkan

Ahmad Ali Riyadi dan

Fahrurrozi. Yogyakarta:

IRCiSoD.

Sugiyono. 2009. Metode Penelitian

Pendidikan: Pendekatan

Kauntitatif, Kualitatif, dan $R$ \& D. Bandung: Alfabeta.

Sumardjoko, Bambang. 2010. Membangun

Budaya Pendidikan Mutu

Perguruan Tinggi: Analisis

Perguruan Tinggi Swasta

di Surakarta. Yogyakarta:

Pustaka Pelajar.

Sutrisno, Edy. 2009. Manajemen Sumber Daya Manusia. Jakarta: Kencana Predana Media Group.

Tampubolon, Daulat P. 2001. Perguruan Tinggi Bermutu: Paradigma Baru Manajemen Pendidikan Tinggi Menghadapi Tantangan Abad ke-21. Jakarta: Gramedia Pustaka Utama.

Undang-Undang Republik Indonesia Nomor 14 Tahun 2005 tentang Guru dan Dosen. Bandung: Citra Umbara.

Undang-Undang Republik Indonesia Nomor 20 Tahun 2003 tentang Sisdiknas.

Jakarta: Biro Hukum dan Organisasi Sekjen Depdiknas.

Wijatno, Serian. 2009. Pengelolaan Perguruan Tinggi Secara Efisien, Efektif, dan Eknomis: Untuk Meningkatkan Mutu penyelenggaraan Pendidikan dan Mutu Lulusan. Jakarta: Salemba Empat.

Yorke, M. 1999. Assuring Quality and Standards in Globalize Higher Education, Journal. Volume 7 Number 1, 1999, MCB University Press. 